\title{
A ANÁLISE DE DISCURSO E A CONSTITUIÇÃO DE UMA HISTÓRIA DAS IDEIAS LINGUÍSTICAS DO BRASIL ${ }^{1}$
}

\section{THE DISCOURSE ANALYSIS AND THE CONSTITUTION OF A HISTORY OF LINGUISTIC IDEAS IN BRAZIL}

\author{
Ana Cláudia Fernandes Ferreira \\ Universidade Estadual de Campinas, Unicamp, Campinas, SP, Brasil
}

\begin{abstract}
Resumo: Neste trabalho, apresento uma história de uma perspectiva discursiva da História das Ideias Linguísticas no Brasil. Inicialmente, lembro a criação de projetos, disciplinas e linhas de pesquisa no espaço das instituiçôes acadêmicas brasileiras; na sequência, enfatizo a importância de certos conceitos e noçôes da análise de discurso que contribuíram fortemente para a delimitação de alguns contornos para essa área no espaço brasileiro. Considero que essa área tornou-se ampla, heterogênea e, ao mesmo tempo, produziu seus modos específicos de fazer história nas condições de produção próprias do conhecimento linguístico no Brasil.

Palavras-chave: Institucionalizaçāo; História das Ideias Linguísticas; Análise de Discurso; Conhecimento Linguístico; Brasil.
\end{abstract}

Abstract: In this work I make an history of a discursive perspective of the history of linguistic ideas in Brazil. It concerns the creation of projects, disciplines and lines of research, within the space of the Brazilian academic institutions. I emphasize the importance of certain notions of the discourse analysis which have contributed greatly to the delimitation of some of the contours of this domain in Brazilian space. An area that has become broad, heterogeneous and, at the same time, has produced its specific means of making history in the Brazilian conditions of production of linguistic knowledge.

Keywords: Institutionalization; History of Linguistic Ideas; Discourse Analysis; Linguistic knowledge; Brazil.

\section{Consideraçóes sobre a institucionalizaçáo da História das Ideias Linguísticas no Brasil}

No Brasil, o modo pelo qual a institucionalização das pesquisas em História das Ideias Linguísticas iniciou foi norteador para a maneira como

1 Uma versão mais resumida deste trabalho foi apresentada no Simpósio "Le discours et ses modes d'historicisation : entre le politique et le disciplinaire ", organizado por Amanda Scherer, Vanise Medeiros, Verli Petri et Cristiane Dias na Conférence Internationale d'Histoire des Sciences du Langage (14th International Conference on the History of the Language Sciences - ICHoLS XIV), realizada em Paris pelo Laboratoire d'Histoire des Théories Linguistiques e pela Société d'Histoire et d'Épistémologie des Sciences du Langage, com o apoio da Université Paris Diderot, da Univesité Paris Sorbonne Nouvelle, do CNRS e do EFL LabEx. 
esse nome - História das Ideias Linguísticas - significa enquanto designação de um domínio de conhecimento, ao lado de outros nomes, notadamente, o nome Análise de Discurso.

Isso está relacionado ao fato de que essas pesquisas começaram no Departamento de Linguística do Instituto de Estudos da Linguagem da Unicamp a partir de um projeto da área de Análise de Discurso. Tratase do projeto "Discurso, Significação, Brasilidade", iniciado em 1987, sob coordenação de Eni Orlandi, que propunha estudar como, em nossa história, no Brasil, discursos sobre a nossa identidade foram sendo construídos: discursos que fazem com que nos signifiquemos como brasileiros.

A respeito das condiçóes de produção que deram ao domínio da História das Ideias Linguísticas no Brasil alguns contornos decisivos, Orlandi (2001) nos lembra que seu livro Terra à Vista, publicado em 1990, já contemplava a questão da identidade do sujeito brasileiro em nossa história. Além disso, essa questão já comparecia articulada a preocupaçôes que envolvem, ao mesmo tempo, ética, política linguística e descolonização científica, preocupaçóes essas que foram amplamente desenvolvidas já nos primeiros projetos História das Ideias Linguísticas.

No período de 1987 a 1988, quando realizava um estágio de pósdoutorado na França, Eni Orlandi tomou conhecimento do projeto de História das Ideias Linguísticas coordenado por Sylvain Auroux, na Universidade de Paris VII, pelo Laboratório de Histoire des Théories Linguistiques do CNRS. No ano seguinte, foi assinado um convênio entre a Unicamp e a Universidade de Paris VII e, em 1992, a equipe brasileira e a francesa deram início ao projeto "História das Ideias Linguísticas: Construção de um saber metalinguistico e a constituição da língua nacional". Esse projeto coletivo contribuiu para um fortalecimento das relaçóes de colaboração com outras universidades e instituiçóes de pesquisa do Brasil e do exterior, tornando possível a oficialização de um Programa de Pesquisas, do qual destaco seus três principais projetos, os quais foram desenvolvidos com apoio do acordo Capes/Cofecub: 


\begin{tabular}{|l|l|l|}
\hline Período & $\begin{array}{l}\text { Projetos do Programa HIL com } \\
\text { apoio do acordo Capes/Cofecub }\end{array}$ & Coord. Brasil/ Coord. França \\
\hline $\mathbf{1 9 9 2 - 1 9 9 5}$ & $\begin{array}{l}\text { Construçáo de um Saber Metalin- } \\
\text { guístico e a Constituiçấo da Língua } \\
\text { Nacional } \\
\text { (no 138/93/97) }\end{array}$ & $\begin{array}{l}\text { Eni Orlandi (Unicamp) } \\
\text { Sylvain Auroux (Université } \\
\text { Paris VII) }\end{array}$ \\
\hline $\mathbf{1 9 9 6 - 2 0 0 3}$ & $\begin{array}{l}\text { Ética e Política das Línguas } \\
\text { (no 313/00/02) }\end{array}$ & $\begin{array}{l}\text { Eni Orlandi (Unicamp) } \\
\text { Diana Luz Pessoa de Barros } \\
\text { (USP) } \\
\text { Sylvain Auroux (ENS Fonte- } \\
\text { nay/Saint-Cloud) }\end{array}$ \\
\hline 2005-2008 & $\begin{array}{l}\text { O Controle Político da Representação: } \\
\text { Uma História das Ideias } \\
\text { (no 490/05) }\end{array}$ & $\begin{array}{l}\text { Eduardo Guimarães (Uni- } \\
\text { camp) } \\
\text { Jean-Claude Zancarini (ENS- } \\
\text { LSH) }\end{array}$ \\
\hline
\end{tabular}

Quadro 1: Projeto do Programa História das Ideias Linguisticas - HIL com apoio do acordo Capes/Cofecub.

Fontes: Site do Programa HIL no Brasil'²; Plataforma Lattes; Orlandi (2001); Estatísticas Capes/Cofecub ${ }^{3}$.

A respeito das relaçóes de colaboração institucional no Brasil, a oficialização de convênios entre a Universidade Federal de Santa Maria, pelo Programa Nacional de Cooperação Acadêmica - Procad/CAPES, e entre a Universidade do Estado do Mato Grosso, pelo Programa de Qualificação Institucional - PQI/CAPES, por exemplo, realizados nos inícios dos anos 2000, contribuíram para uma importante expansão das pesquisas em História das Ideias Linguísticas no país. Em um movimento de expansão dessas pesquisas a partir dos anos 2000, vários outros projetos de diferentes tipos foram realizados em diversas instituiçóes brasileiras: projetos docentes, projetos de pesquisadores do $\mathrm{CNPq}$, projetos de iniciação científica, de mestrado e de doutorado, muitos deles financiados por agências de fomento estaduais ou federais e firmados por acordos internacionais, como projetos

2 Disponível em: <http://www.Unicamp.br/iel/hil>. Acesso em: out. 2018

3 Disponível em: <http://www.capes.gov.br/images/stories/download/bolsas/1572015Estatisticas-CapesCOFECUB-1978-2015.pdf>. Acesso em: out. 2018. 
de doutorado sanduíche e de pós-doutorado.

Nesse movimento de expansão, a institucionalização de linhas de pesquisa, de disciplinas em História das Ideias Linguísticas, bem como de disciplinas que levam em conta essa área em cursos de graduaçáo e de pósgraduação se ampliou para universidades brasileiras de todas as regióes do país. Isso vem resultando numa quantidade massiva de dissertaçóes e de teses defendidas em História das Ideias Linguísticas ou articuladas a essa área; dessas muitas, posteriormente, foram publicadas em forma de livro. Paralelamente, inúmeros outros tipos de publicação têm surgido, e uma série de eventos científicos em História das Ideias Linguísticas - ou com significativa presença dessa área - tem sido realizada ${ }^{4}$. Hoje, portanto, a difícil tarefa de recensear o amplo volume de pesquisas, de projetos, de disciplinas, de áreas, de linhas de pesquisa, além de eventos e publicaçóes variadas, inclusive de trabalhos desenvolvidos a partir de outras filiaçóes teóricas nessa área nomeada de História das Ideias Linguisticas, é um efeito dessa institucionalização.

Se, de um lado, os primeiros projetos de História das Ideias Linguísticas se produziram a partir de uma articulação forte com a Análise de Discurso, de outro, eles também puderam integrar pesquisadores de diversas instituiçóes universitárias brasileiras, inscritos em áreas diferentes, como, por exemplo: sintaxe, semântica, análise de discurso, semiótica, pragmática, sociolinguística, linguística indígena, lexicologia, filosofia da linguagem, história, estudos clássicos, ciências da informação e da cognição e literatura.

Para o presente trabalho, limitei-me a traçar algumas consideraçóes gerais sobre o papel e os efeitos da Análise de Discurso, na linha dos trabalhos produzidos a partir de Michel Pêcheux, na França, e de Eni Orlandi, no Brasil, para a institucionalização de uma perspectiva discursiva da História das Ideias Linguísticas no espaço brasileiro. Farei um percurso sobre/entre alguns temas e questôes de pesquisa caros à História das Ideias Linguísticas no Brasil, lembrando, aqui e ali, publicaçôes que trabalham com essa área a partir dessa perspectiva discursiva. A esse respeito, é importante salientar que o conjunto das obras que citarei no decorrer desse trabalho não poderia ser exaustivo (o que seria impossível), mas tão somente ilustrativo.

4 Destaco as Jornadas "História das Ideias Linguísticas", que começaram a ser promovidas a partir dos programas Capes/Cofecub. Vale salientar também que uma das linhas de pesquisa do GT de Análise de Discurso da Anpoll é a linha de "História das Ideias Linguísticas". Isso tem contribuindo significativamente para a sustentação dessa área no espaço brasileiro, em sua relação com a análise de discurso. 


\section{A História das Ideias Linguísticas de uma perspectiva discursiva}

Um ponto de partida fundamental da realização de trabalhos que buscam compreender a história brasileira no âmbito dos primeiros projetos de História das Ideias Linguísticas pode ser depreendido no próprio título do primeiro projeto Capes/Cofecub, que é a relação entre a construção de um saber metalinguístico e a constituição da lingua nacional. Já aí, o papel da análise de discurso é decisivo. A esse respeito, vale lembrar Orlandi e Guimarães (1996b):

A constituição da língua nacional no Brasil é um efeito construído pela história contraditória da gramatização brasileira. No sentido mesmo de que a gramatização de uma língua é parte da história da língua, não sendo, simplesmente, uma produção de instrumentos sobre ela. As tecnologias não são só o resultado de um saber, são também parte dos fatos para os quais, ou a partir dos quais, foram produzidas ${ }^{5}$ (GUIMARÃES, 1996b, p. 13).

Um dos efeitos da consideraçáo de que a construçáo do saber metalinguístico e a constituição da língua nacional são indissociáveis é que ela permitiu o desenvolvimento de uma série de estudos significativos sobre a relação entre a língua e as línguas em sua historicidade ${ }^{6}$. Estudos que se fizeram tomando essa relação discursivamente, entendendo $o$ discurso como a lingua na história. Sobre isso, Orlandi (1998) diz:

Com a noçáo de discurso podemos deslocar o modo como é concebido o papel da língua nacional e sermos críticos à relação geral considerada direta entre língua e nação, o que não deixa de se relacionar com a crítica que fazemos da noção de língua como visão de mundo. A relaçâo língual pensamento/mundo é indireta e bem mais complexa assim como também

5 A história contraditória da gramatização brasileira do português, conforme Guimarães (2011), se dá pelo fato de que a língua nacional do Brasil é a língua de outro povo do qual o Brasil se separou.

6 Importante destacar que essa intervenção teórica da análise de discurso na História das Ideias Linguísticas também contribuiu, de certo modo, sobre a maneira como autores da Semântica da Enunciação vêm produzindo pesquisas em História das Ideias Linguísticas. Conforme observei em Ferreira (2005a, 2006 e 2012), a Semântica da Enunciação é uma disciplina brasileira que se constituiu a partir de um forte diálogo com a Análise de Discurso. Por essa razão, também serão lembrados aqui alguns trabalhos importantes de História das Ideias Linguísticas produzidos nesta área da Semântica, pelo diálogo que estabeleceram com a Análise de Discurso; notadamente, pela mobilização e pela elaboração de alguns conceitos e noçōes decisivos para a História das Ideias Linguísticas. 
o é a relação entre língua, os processos identitários e a nacionalidade (ORLANDI, 1996, p. 7).

Esses estudos sobre a relação entre a língua e as línguas percorreram as tensôes e contradiçóes entre língua imaginária e língua fluida ${ }^{7}$, entre lingua oficial, lingua nacional, lingua materna, lingua estrangeiras ${ }^{8}$ lingua transnacional ${ }^{9}$, lingua de fronteira ${ }^{10}$, e entre língua portuguesa, lingua geral, lingua brasileira ${ }^{11}$ etc. Esses estudos também permitiram problematizar as noçôes cristalizadas de dialeto e de língua, bem como de variação e de mudança, indagando, por exemplo, a partir de Orlandi $(2009)^{12}$ : Por que até

7 Os conceitos de língua imaginária e língua fluida de Orlandi (1985, 1990, 2002a, 2009) e Orlandi e Souza (1988) têm um papel fundamental nas pesquisas de história das ideias linguísticas que consideram a língua discursivamente.

8 Por exemplo: Dias (1995, 2015), Orlandi e Guimarães (Orgs.) (1996a, 2002, 2007), Orlandi e Guimarăes (1996b), Orlandi (1998, 2002a, 2009), Auroux, Orlandi, Mazière (Orgs.) (1998), Silva (1998, 2013), Payer (1999, 2004, 2007), Pfeiffer (2000, 2001, 2011b), Rodríguez (2000), Orlandi (Org.) (2001), Guimarães (2001, 2004, 2005-10, 2011a, 2011b), Morello (2001), Lagazzi (2002), Oliveira (2002), Augustini (2003-2004), Mariani (2004), Schumm (2004, 2009), Di Renzo (2005), Joanilho (2005), Almeida (2006, 2011), Sturza (2006), Fragoso (2006), Mariani e Jobim (2007), Castelo Branco (2007, 2013), Diniz (2008, 2012), Garcia (2008), Almeida (2008), Bisinoto (2008), Cervo (2008, 2012), Zoppi-Fontana (Org.) (2009a), Zoppi-Fontana (2009b, 2013, 2015), Caldas (2009), Mariani e Medeiros (2010), Borges e Ferreira (2010), Silva (2010), Esteves (2010), Fedatto (2011, 2013), Schreiber da Silva e Santos (2011), Machado, C. (2011), Silva Sobrinho (2011), Aquino (2012), Celada (2013), Borges (2013), Buscacio (2014), Karim e Di Renzo (2015), Colaça (2015), Costa (2015), Freitas (2015), Petri, Schneiders e Scherer (2015), Silvestre (2016), Medeiros (2016a), Schneiders (2017), Scherer, Costa e Biliāo (2017) e Silva e Bressanin (2017). Lembro tambéma revista Línguas e InstrumentosLinguísticos, publicada desde 1998; os números 42 e 46 da revista Letras, de 2011 e 2013, respectivamente, e a Seção "Redes Discursivas na História das Ideias Linguísticas" em Maluf-Souza, Silva, Almeida e Bisinoto (2012).

9 Por exemplo: Zoppi-Fontana (Org.) (2009a), Zoppi-Fontana (2009b) e Baalbaki (2012).

10 Por exemplo: Sturza (2006) e Silva e Bressanin (2017).

11 Por exemplo: Orlandi (1985, 1990, 2002a, 2009) e de Orlandi e Souza (1988), Dias (1995, 2015), Orlandi e Guimarães (Orgs.) (1996a, 2002, 2007), Auroux, Orlandi, Mazière (Orgs.) (1998), Payer (1999, 2004, 2007), Orlandi (Org.)(2001), Lagazzi (2002), Guimarães (2004, 2005-10, 2011b), Mariani (2004), Schumm (2004, 2009), Almeida (2006, 2011), Castelo Branco (2007, 2013), Bisinoto (2008), Garcia (2008), Silva Sobrinho (2011), Ferreira e Faria (2016), Ferreira e Nogueira (2016), Schneiders (2017), Scherer, Costa e Bilião (2017), a revista Línguas e Instrumentos Linguísticos, desde 1998; os números 42 e 46 da revista Letras de 2011 e 2013, respectivamente, e a Seção "Redes Discursivas na História das Ideias Linguísticas" em Maluf-Souza, Silva, Almeida e Bisinoto (2012).

12 A autora diz: "Vale ainda ressaltar que todos reconhecem as mudanças quando se trata da diferença entre o latim e uma das línguas românicas, como por exemplo, o português. Mas não se vêem mais línguas mudando. E não se "reconhece" a mudança quando se trata da que existe entre o português e o brasileiro" (ORLANDI, 2009, p. 49). 
o século XIX se fala de mudança e depois disso só há variação? ${ }^{13}$

Ao lado disso, esses estudos levaram ao desenvolvimento de teses sobre diferentes tipos de gramatização, articulando a gramatizaçâo portuguesa, com a gramatizaçáo brasileira do português ${ }^{14}$ e a gramatização brasileira do brasileiro $^{15}$; levaram também à produção de uma quantidade considerável de publicaçôes sobre a história da gramatização brasileira ${ }^{16}$, sobre a institucionalização da linguística e a disciplinarização das ideias linguísticas no Brasil ${ }^{17}$, bem como a respeito da história do ensino no espaço brasileiro ${ }^{18}$, publicaçôes que estâo articuladas a essa perspectiva discursiva.

É dessa perspectiva discursiva e antes mesmo da criação dos projetos dos acordos Capes/Cofecub, que Eni Orlandi, ao apresentar a obra Politica

13 Também vale lembrar Orlandi (2014) e Ferreira e Faria (2016), por exemplo.

14 Esta noção fundamental, constantemente mobilizada em inúmeras pesquisas de história das ideias linguísticas no Brasil, foi formulada por Orlandi e Guimarães (1996b, 2002).

15 Ferreira e Nogueira (2016).

16 Por exemplo: Orlandi e Guimarães (Orgs.) (1996a, 2002, 2007), Orlandi e Guimarães (1996b), Nunes (1996, 2002, 2009), Silva (1998, 2013), Baldini (1999), Pfeiffer (2000, 2011b), Orlandi (Org.)(2001), Orlandi (2002a, 2009), Oliveira (2002), Augustini (2003), Guimarães (2004, 2011a), Almeida (2006), Fragoso (2006), Machado (2007, 2011), Bisinoto (2008), Diniz (2008), Garcia (2008, 2011, 2012), Scotta (2008), Costa (2010, 2016), Silva Sobrinho (2011), Schneideres (2011, 2014), Lagazzi (2012), Medeiros e Mattos (2012), Dias (2012, 2014, 2016), Petri (2012), Celada (2013), Santos (2013), Medeiros (2014, 2016a, 2016b), Esteves (2014),Petri, Schneiders e Scherer (2015), Ferreira e Nogueira (2016), Ferreira e Faria (2016),Aquino (2016), Freitas (2016) e Schneiders e Reisdorfer (2017), a revista Línguas e Instrumentos Linguísticos, desde 1998; o número 42 da revista Letras, de 2011, e a Seção "Redes Discursivas na História das Ideias Linguísticas" em Maluf-Souza, Silva, Almeida e Bisinoto (2012).

17 Por exemplo: Orlandi (2002a, 2002b, 2009, 2014), Orlandi e Guimarães (Orgs.) (2002, 2007), Lagazzi (2002), Guimarães (2004), Baldini (2005),Scherer (2005), Ferreira (2005a, 2006, 2009, 2012), Martins (2008, 2012), Almeida (2008), Cervo (2008), Moura (2008), Nunes (2008), Dias (2008), Schneiders (2011, 2014), Pfeiffer (2012, 2018), Cabral Hayashida (2012), Maluf-Souza, Silva, Almeida e Bisinoto (2012), Scherer e Petri (2012, 2013), Silva (2012), Mariani e Medeiros (2013), Costa (2015), Aquino (2016), Almeida (2017), a revista Línguas e Instrumentos Linguísticos, desde 1998, e o número 42 da Cadernos de Estudos Linguísticos, de 2002.

18 Por exemplo: Orlandi e Guimarães (Orgs.) (1996a, 2002), Silva (1998, 2012, 2013), Payer (1999, 2004, 2007), Pfeiffer (2000, 2011a, 2011b), Orlandi (Org.) (2001), Orlandi (2002a, 2009, 2014), Guimarães (2005-10), Di Renzo (2005, 2014), Bisinoto (2008), Diniz (2008), Zoppi-Fontana (Org.)(2009a), Zoppi-Fontana (2009b), Silva (2010), Luz (2010), Baalbaki (2012), Sarian (2012), Scherer e Petri (2012, 2013), Mariani e Medeiros (2013), Celada (2013), Colaça (2015), Freitas (2015), Medeiros (2016a), Schneiders e Reisdorfer (2017), Silva e Bressanin (2017), a revista Línguas e Instrumentos Linguísticos, desde 1998, o número 46 da revista Letrase a Seção "Redes Discursivas na História das Ideias Linguísticas" em Maluf-Souza, Silva, Almeida e Bisinoto (2012). 
Linguistica na América Latina (Org., 1988), já pelo título significativo "Confronto pela linguagem", lembra, de início, que "Falar é, em si, uma prática política”. Sua apresentação abre uma importante via de reflexão para pensar a noçáo de política linguística mais amplamente, considerando que ela diz respeito não somente às intervençóes visíveis produzidas pelas instâncias institucionais e pelo Estado. Do ponto de vista discursivo, há diferentes políticas linguísticas funcionando em todas as instâncias de uma sociedade em processos bem menos evidentes.

Já com os projetos de História das Ideias Linguísticas, notadamente a partir do segundo projeto, intitulado "Ética e politica das linguas", diversos trabalhos foram produzidos pensando a política linguística e as políticas das línguas da perspectiva de que o político é constitutivo das práticas discursivas. Vale destacar aqui os trabalhos de Orlandi (1998) e Guimarães (2001) sobre ética e política das línguas, tendo em vista as tensóes e contradiçóes constitutivas das relaçôes entre unidade, diversidade e dominação. Também vale destacar a distinção de Mariani (2004) entre políticas linguísticas e políticas de sentidos das linguas ${ }^{19}$. Vários desses estudos estáo ligados a reflexôes sobre colonizaçâa linguistica, descolonização linguistica, e discussóes sobre lusofonia e antilusitanismo ${ }^{20}$.

A partir da intervenção da análise de discurso na História das Ideias linguísticas, é possível compreender a noção de instrumento linguístico ${ }^{21}$

19 Lembro ainda Orlandi (1985, 1990, 1993b, 1993c, 2002a, 2002b, 2007b, 2009, 2014), Orlandi (Org.) (1988, 1993a, 2001, 2007a), Orlandi e Souza (1988), Orlandi e Guimarães (1996a, 2002, 2007), Dias (1995, 2015), Nunes (1996, 2002, 2009), Silva (1998, 2012, 2013), Baldini (1999), Payer (1999, 2004, 2007), Pfeiffer (2000, 2001, 2011a, 2011b, 2012, 2018), Rodriguez (2000), Morello (2001), Lagazzi (2002), Oliveira (2002, 2004), Guimarães (2004), Mariani (2004), Schumm (2004, 2009), Di Renzo (2005, 2014), Scherer (2005), Machado (2007, 2011), Castelo Branco (2007, 2013), Diniz (2008, 2012, 2013), Zoppi-Fontana (Org.) (2009a), Zoppi-Fontana (2009b, 2013, 2015), Ferreira (2009), Mariani e Medeiros (2010), Costa (2010), Esteves (2010), Fedatto (2011, 2013, 2015), Silva Sobrinho (2011), Schreiber da Silva e Santos (2011), Scherer e Petri (2012, 1013), Cervo (2012), Celada (2013), Borges (2013), Oliveira (2014), Colaça (2015) e Silvestre (2016), a revista Línguas e Instrumentos Linguísticos, desde 1998; os números 42 e 46 da revista Letras, de 2011 e2013, respectivamente, e a Seção "Redes Discursivas na História das Ideias Linguísticas" em MalufSouza, Silva, Almeida e Bisinoto (2012).

20 Por exemplo: Orlandi (1990, 1993a, 2002a, 2007b, 2009, 2014), Mariani (2004), Mariani e Jobim (2007), Castelo Branco (2007, 2013), Diniz (2008, 2012), Zoppi-Fontana (Org.) (2009a), Zoppi-Fontana (2009b), Silva Sobrinho (2011), Celada (2013), Fedatto (2015) e Silvestre (2016).

21 Noção elaborada por Sylvain Auroux (1992, p. 69) que compreende a gramática e o dicionário como instrumentos que prolongam e transformam a fala natural. 
de uma maneira particular: como objeto histórico, como discurso $0^{22}$. Essa noção, ao ser pensada em relação às conjunturas brasileiras de produção de saber linguístico, envolve, além da gramática e do dicionário, outros objetos históricos, tais como relatos de viajantes e de missionários, manuais, cartilhas, glossários, enciclopédias, programas, parâmetros curriculares, museus, nomenclaturas, manifestos, etc ${ }^{23}$. Nesse amplo conjunto de trabalhos, a história da língua, das línguas, dos instrumentos linguísticos, da linguística e das disciplinas a elas relacionadas se configura como uma história de sentidos.

Outro aspecto importante a destacar dessas produçóes é que a filiação à Análise de Discurso levou diversos pesquisadores a um trabalho refletido sobre o arquivo, a partir do que propôs Pêcheux (1997 [1982], p. 63): tomar a materialidade da língua na discursividade do arquivo, e também a partir de Guillaumou e Maldidier (1997 [1986], p. 164): “O arquivo nunca é dado a priori, e em uma primeira leitura, seu funcionamento é opaco" ${ }^{24}$.

Ao lado dos conceitos de discurso, língua e história, uma noçáo bastante produtiva para a pesquisa em História das Ideias Linguísticas é a de discurso fundador, que joga com os sentidos já estabilizados, o sem sentido, o não sentido e a irrupção de novos sentidos ${ }^{25}$. Tal noção foi fundamental para minhas investigaçôes sobre a história de sentidos da palavra linguística no espaço institucional da Unicamp ${ }^{26}$. Nessas investigaçôes, pude compreender

22 A esse respeito, cabe salientar que, antes mesmo da constituiçáo de um programa de História das Ideias Linguísticas na França, no início de 1980, já havia trabalhos de análise de discurso sobre os sentidos de palavras em diferentes dicionários, como, por exemplo, o trabalho de Delesalle e Valensi (1972). Também vale lembrar dos textos de Mazière $(1989,1995)$ e Collinot e Mazière (1997) no espaço francês, e Orlandi e Guimarães (Orgs.) (1996a,2002, 2007), Nunes (1996, 2002, 2009), Orlandi (Org.) (1998, 2001), Orlandi (2002a, 2009) e Oliveira (2004) no espaço brasileiro. Conferir também as produçôes citadas na nota 13 sobre a gramatização brasileira.

23 Por exemplo: Nunes (1996, 2002), Baldini (1999), Silva Sobrinho (2011), Petri (2012), Garcia (2012), Diniz (2012), Celada (2013), Ferreira e Faria (2016), Medeiros (2016a), Guimaráes (2011a), Schneiders e Reisdorfer (2017), e a revista Línguas e Instrumentos Linguísticos, desde 1998.

24 Por exemplo: Silva (1998), Petri (2000), Ferreira (2005a, 2009, 2015), Nunes (2008b), Garcia (2008, 2011), Buscacio (2014) e Schneiders (2014a).

25 Esta noçáo, proposta por Orlandi (1993b, 1993c), foi tratada sob diferentes formas na obra por ela organizada (ORLANDI, 1993a). Diversas pesquisas de história das ideias linguísticas passaram a mobilizar essa noção, como, por exemplo: Nunes (1996), Silva (1998), Baldini (1999), Pfeiffer (2000), Sturza (2006), Almeida (2008), Ferreira (2009), Fedatto (2011), Medeiros e Mattos (2012), Petri, Schneiders e Scherer (2015), Aquino (2016) e Schneiders (2017).

26 Ferreira (2009). 
como duas formulações cristalizadas - A linguística é a ciência da linguagem e A linguistica é a ciência-piloto das ciências humanas - significaram imaginariamente como referência e como lugar de origem do dizer na constituição da linguística, primeiramente, no Instituto de Filosofia e Ciências Humanas e, depois, no Instituto de Estudos da Linguagem dessa universidade.

Mais recentemente, diferentes pesquisas vêm indagando sobre instrumentos linguísticos ligados à terceira revolução tecnolinguística (AUROUX, 1998), na qual está inserida, inclusive, a internet. A constituição e o papel de instrumentos linguísticos próprios dessa revolução, como o buscador do Google, o dicionário do Google, outros dicionários e enciclopédias digitais online, bem como os novos "recursos educacionais" da internet também se tornaram objeto de trabalhos de pesquisadores brasileiros que articulam História das Ideias Linguísticas e Análise de Discurso ${ }^{27}$.

Os temas e questóes em História das ideias Linguísticas, a partir da perspectiva discursiva que procurei destacar neste trabalho, podem ser resumidos nos seguintes tópicos:

a. Indissociabilidade entre a construção do saber metalinguístico e a constituição da língua nacional;

b. A relação entre a língua e as línguas tomada discursivamente, entendendo o discurso como a lingua na história;

c. Tensôes e contradiçóes entre língua imaginária, lingua fluida, lingua portuguesa, lingua brasileira, lingua geral, lingua oficial, lingua nacional, lingua materna, lingua transnacional, lingua estrangeira, lingua de fronteira, etc.;

d. Problematização de noçôes de dialeto e língua, de variação e mudança;

e. Gramatização brasileira do português e gramatização brasileira do brasileiro;

f. O político como constitutivo das práticas discursivas;

g. Reflexão sobre ética, política e consideração de diferentes tipos de políticas linguísticas de uma perspectiva discursiva;

h. Colonizaçâo linguística, descolonização linguística, e discussão sobre

27 Por exemplo: Ferreira (2015), Ferreira e Faria (2016) Nakamura (2016) e Freitas (2016). 
lusofonia e antilusitanismo;

i. O instrumento linguístico como objeto histórico, como discurso;

j. Manuais, livros, glossários, enciclopédias, programas, parâmetros curriculares, museus, etc., como instrumentos linguísticos ou em relação a eles;

k. A história como história de sentidos, considerando o discurso como inscrição material da língua na história;

1. A discursividade do arquivo;

$\mathrm{m}$. A produtividade da noção de discurso fundador;

n. A discursividade dos instrumentos linguísticos ligados à terceira revolução tecnolinguística.

Cabe salientar que esses tópicos náo devem ser tomados como uma síntese de todas as questôes que contribuíram para a produção de um delineamento específico à área de História das Ideias Linguísticas no espaço brasileiro. No entanto, eles permitem dar uma visibilidade importante a esse delineamento.

\section{Consideraçóes conclusivas sobre a História das Ideias Linguísticas do Brasil}

Embora a relação entre a História das Ideias Linguísticas e a Análise de Discurso não seja necessária e nem compareça em todo o amplo e heterogêneo conjunto de produçôes de pesquisadores brasileiros, ela é fundante para a constituição dessa área no Brasil e, ao mesmo tempo, decisiva para uma parte significativa dessas produçóes.

A História das Ideias Linguísticas delineada no Brasil em sua filiação à Análise de Discurso vem indagando sobre os instrumentos linguísticos e suas relaçôes com as instituiçôes, o Estado, o mercado, a globalização, bem como com os novos modos de significação do sujeito em relação à identidade e à autoria e, ainda, em relação aos movimentos de resistência às formas de conformação técnica. É nesse sentido que podemos dizer que, dessa perspectiva, quaisquer práticas técnicas são, necessariamente, práticas políticas.

Tomar discursivamente a relação do sujeito com seus instrumentos na História das Ideias Linguísticas implica considerar que, se os instrumentos 
linguísticos são artifícios que prolongam e transformam a inteligência humana ${ }^{28}$, a relação entre o sujeito e seus artifícios na sociedade é necessariamente histórica, mas em um sentido teórico bem particular: é histórica na medida em que é perpassada pelo simbólico, pela ideologia, pelo discurso.

Essas pesquisas têm investigado produtivamente a nossa história específica no Brasil e vêm contribuindo de maneira forte para o processo de descolonização linguistica e descolonização científica. É parte desse processo o fato de que, hoje, o pesquisador brasileiro se permite colocar em um espaço particular para falar das ideias linguísticas no Brasil e também no mundo ${ }^{29}$. Nesse sentido, retomando uma formulação de minhas pesquisas sobre a história da linguística ${ }^{30}$, podemos dizer que não estamos mais apenas no domínio da História das Ideias Linguísticas no Brasil, mas no domínio da História das Ideias Linguísticas do Brasil.

\section{Referências}

ALMEIDA, Agnaldo. A posição-sujeito gramático ocupada por Evanildo Bechara na mídia: tradição e/ou modernidade? Revista de Estudos da Linguagem, v. 25, p. 765-790, 2017.

ALMEIDA, Eliana de. Folhetim: uma crônica da língua. 2016. Tese (Doutorado) - Instituto de Estudos da Linguagem, Universidade Estadual de Campinas, Campinas, 2006.

. Poesia: uma História das Ideias Linguísticas. In: DI RENZO, Ana; MOTTA, Ana Luiza Artiaga Rodrigues; OLIVEIRA, Tânia Pitombo de. (Orgs.). Linguagem, História e Memória: discursos em movimento. Campinas: Pontes, 2011. p. 103-112.

ALMEIDA, Suely Pessanha de. Língua, ensino e nacionalidade no Instituto de Educação do Rio de Janeiro (1880-1932): uma contribuição

28 Auroux (1992, 1998).

29 Por exemplo: Orlandi (2002b, 2013), Ferreira (2005b), Machado, I. (2011, 2015), Oliveira (2015) e Ribeiro (2016).

30 Ferreira (2009). 
à História das Ideias Linguísticas. 2008. Tese (Doutorado) - Universidade Federal Fluminense, Niterói, 2008.

AQUINO, José Edicarlos de. O que há de materno na língua? Consideraçôes sobre os sentidos de língua materna no processo de gramatização brasileira nos séculos XIX a XX. 2012. Dissertação (Mestrado) - Instituto de Estudos da Linguagem, Universidade Estadual de Campinas, Campinas, 2012.

Júlio Ribeiro na história das ideias linguísticas no Brasil. 2016. Tese (Doutorado) - Instituto de Estudos da Linguagem, Universidade Estadual de Campinas, Campinas, 2016.

AUGUSTINI, Carmen Lúcia Hernandes. A enunciaçáo do transbordamento das regras: a estilística no discurso da gramática. 2003. Tese (Doutorado) - Instituto de Estudos da Linguagem, Universidade Estadual de Campinas, Campinas, 2003.

AUROUX, Sylvain. A revoluçáo tecnológica da gramatização. Campinas: Unicamp, 1992.

A filosofia da linguagem. Campinas: Unicamp, 1998.

AUROUX, Sylvain; ORLANDI, Eni; MAZIÈRE, Francine (Dirs.). L'hyperlangue brésilienne. Langages, 32e année, n. 130, 1998.

BAALBAKI, Angela Corrêa Ferreira. A formação de professores de português na Argentina: a configuração de um espaço de enunciação transnacional. Anais do SIELP, v. 2. Uberlândia: EDUFU, p. 01-13, 2012.

BALDINI, Lauro. A Nomenclatura Gramatical Brasileira interpretada, definida, comentada e exemplificada. 1999. Dissertação (Mestrado) Instituto de Estudos da Linguagem, Universidade Estadual de Campinas, Campinas, 1999.

Um linguista na terra da gramática. 2005. Tese (Doutorado) Instituto de Estudos da Linguagem, Universidade Estadual de Campinas, 
Campinas, 2005.

BISINOTO, Leila Salomão Jacob. Migraçóes Internas, Norma e Ensino da Língua Portuguesa. 2008. Tese (Doutorado) - Instituto de Estudos da Linguagem, Universidade Estadual de Campinas, Campinas, 2008.

BORGES, Águeda Aparecida da Cruz; FERREIRA, Lucimar Luisa. Para uma História das Ideias linguísticas: uma reflexáo sobre a resistência do povo Xavante pela língua. Libro de Actas. Buenos Aires: Conicet, 2010.

BORGES, Julie Kellen de Campos. As denominaçóes do imigrante nas políticas de imigraçáo no Estado de Sáo Paulo: a produção da diferença. 2013. Tese (Doutorado) - Instituto de Estudos da Linguagem, Universidade Estadual de Campinas, Campinas, 2013.

BUSCACIO. Lívia Leticia Belmiro. Mário de Andrade, um arquivo de saberes sobre a língua do/no Brasil. 2014. Tese (Doutorado) Universidade Federal Fluminense, Niterói, 2014.

CABRAL HAYASHIDA, Sandra Raquel de Almeida. Periódicos científicos: a produção e a circulação da ciência da linguagem no Brasil. 2012. Tese (Doutorado) - Instituto de Estudos da Linguagem, Universidade Estadual de Campinas, Campinas, 2012.

CADERNOS de Estudos Linguísticos. História das Ideias Linguísticas. n. 42, 2002.

CALDAS, Beatriz Fernandes. Discursos sobre/de traduçáo no Brasil: Línguas e Sujeitos. 2009. Tese (Doutorado) - Universidade Federal Fluminense, Niterói, 2009.

CASTELO BRANCO, Luiza Kátia Andrade. Historicidade e sentidos: a palavra 'crioulo' nos discursos sobre a língua de Cabo Verde. 2007. Dissertação (Mestrado) - Universidade Federal Fluminense, Niterói, 2007. 
A língua em além-mar: sentidos à deriva - o discurso da CPLP sobre a língua portuguesa. 2013. Tese (Doutorado) - Instituto de Estudos da Linguagem, Universidade Estadual de Campinas, Campinas, 2013.

CELADA, Maria. Teresa. Instrumentos linguísticos na enseñanza del E/LE en Brasil: procesos de descolonización e interfaces entre lengua y contexto(s). Palestra. I Jornada de Capacitação APEESP/SEE-SP, 2013.

CERVO, Larissa Montagner. Do lugar do linguista e da língua como objeto de divulgaçáo. 2008. Dissertação (Mestrado em Letras) Universidade Federal de Santa Maria, Santa Maria, 2008.

Língua, patrimônio nosso. 2012. Tese (Doutorado em Letras) Universidade Federal de Santa Maria, Santa Maria, 2012.

COLLINOT, André; MAZIÈRE, Francine. Un prêt à parler: le dictionnaire. Paris: Presses Universitaire France, 1997.

COLAÇA, Joyce Palha. O guarani como língua oficial e a promoção de um bilinguismo imaginário no Paraguai. 2015. Tese (Doutorado) Universidade Federal Fluminense, Niterói, 2015.

COSTA, Maria Iraci Sousa. A produçáo do conhecimento sobre a língua na segunda metade do século XX: o funcionamento da contradição. 2015. Tese (Doutorado em Letras) - Universidade Federal de Santa Maria, Santa Maria, 2015.

COSTA, Thais de Araújo da. Gramáticas pós-NGB: do discurso oficial a outros discursos (im)possíveis. 2010. Dissertação (Mestrado) - Universidade Federal Fluminense, Niterói, 2010.

Evanildo Bechara e a(s) moderna(s) gramática(s) portuguesa(s): autoria, (re)produção, (re)formulação, e circulação de dizeres sobre a língua no/do Brasil no século XX. 2016. Tese (Doutorado) - Universidade Federal Fluminense, Niterói, 2016. 
DELESALLE, Simone; VALENSI, Lucette. Le mot "nègre" dans les dictionnaires français d'Ancien régime; histoire et lexicographie. Langue Française: Langage et histoire, p. 79-104, 1972.

DIAS, Juciele Pereira. O lugar e o funcionamento do título pela obra de Mattoso Câmara. 2008. Dissertação (Mestrado) - Universidade Federal de Santa Maria, Santa Maria, 2008.

. Um gesto de interpretaçáo na história do conhecimento linguístico brasileiro: a definição do nome gramática. 2012. Tese (Doutorado em Letras) - Universidade Federal de Santa Maria, Santa Maria, 2012.

A definição do nome gramática na história do conhecimento linguístico brasileiro. In: BAALBAKI, Angela; CALDAS, Beatriz. (Orgs.). Instrumentos linguísticos: usos e atualizaçôes. Araruama: Cartolina, p. 1552, 2014.

Efeitos de sentido da designação moderna na história (das ideias linguísticas) do Brasil. Interfacis, n. 2, p. 1-18, 2016.

DIAS, Luiz Francisco. Sentidos do idioma nacional. As bases enunciativas do nacionalismo linguístico. 1995. Tese (Doutorado) - Instituto de Estudos da Linguagem, Universidade Estadual de Campinas, Campinas, 1995.

. Língua e nacionalidade no Brasil na primeira metade do século XX. Polifonia, Cuiabá, UFMT, v. 22, n. 31, p. 11-31, 2015.

DINIZ, Leandro. Mercado de línguas: a instrumentalização brasileira do português como língua estrangeira. 2008. Dissertação (Mestrado) Instituto de Estudos da Linguagem, Universidade Estadual de Campinas, Campinas, 2008.

Política linguística do Estado brasileiro na contemporaneidade:

a institucionalizaçáo de mecanismos de promoção da língua nacional no exterior. 2012. Tese (Doutorado) - Instituto de Estudos da Linguagem, 
Universidade Estadual de Campinas, Campinas, 2012.

O conceito de política linguística: reflexões a partir do diálogo entre a História das Ideias Linguísticas, a Análise do Discurso e a Semântica do Acontecimento. In: COSTA, Greciely Cristina da; MASSMANN, Débora (Orgs.). Linguagem e Historicidade. Campinas: RG, 2013. p. 43-58.

DI RENZO, Ana Maria. A constituiçáo do Estado brasileiro e a imposiçáo do Português como Língua Nacional. 2005. Tese (Doutorado) - Instituto de Estudos da Linguagem, Universidade Estadual de Campinas, 2005.

. Escola e a formação de políticas linguísticas. Letras, n. 48, p. 3952, 2014 .

ESTEVES, Phellipe Marcel da Silva. A translação de sentidos ente língua e classe social. 2010. Dissertação (Mestrado) - Universidade Federal Fluminense, Niterói, 2010.

. O que se pode e se deve comer: uma leitura discursiva sobre o sujeito e alimentação nas enciclopédias brasileiras (1863-1973). 2014. Tese (Doutorado) - Universidade Federal Fluminense, Niterói, 2014.

FEDATTO, Carolina Padilha. Um saber nas ruas: o discurso histórico sobre a cidade brasileira. 2011. Tese (Doutorado) - Instituto de Estudos da Linguagem, Universidade Estadual de Campinas, 2011.

Saber linguístico e história urbana: a produção do nós nacional. Línguas e Instrumentos Linguísticos, n. 31, p. 75-89, 2013.

Antilusitanismo. Revista de estudos de cultura. São Cristóvão, UFS, v. 1. p. 53-60, 2015.

FERREIRA, Ana Cláudia Fernandes. Um nome de teoria estabilizado, sentidos em movimento: a semântica argumentativa na história. 2005. Dissertação (Mestrado) - Instituto de Estudos da Linguagem, Universidade 
Estadual de Campinas, Campinas, 2005a.

Os sentidos de semântica lingüística nos primeiros estudos de Oswald Ducrot. Estudos Lingüísticos XXXIV, p. 1128-1133, 2005 b.

O Conceito de interdiscurso na semântica da enunciação. II Seminário de Estudos em Análise do Discurso, Porto Alegre: UFRGS, 2006. p. 01-08.

A línguística entre os nomes da linguagem. Uma reflexão na História das Ideias Linguísticas no Brasil. 2009. Tese (Doutorado) - Instituto de Estudos da Linguagem, Universidade Estadual de Campinas, 2009.

. Um percurso pela história da semântica da enunciação. WebRevista Discursividade: Estudos Linguísticos, v. 9, p. 1-26, 2012.

O papel e o poder fundador da linguagem na reflexão sobre conhecimento e tecnologia. Entremeios: revista de estudos do discurso, n. 11, p. 75-98, 2015.

FERREIRA, Ana Cláudia Fernandes; NOGUEIRA, Luciana. A colocação dos pronomes na Grammatica Portugueza de Júlio Ribeiro. Línguas e Instrumentos Linguísticos, n. 38, p. 11-33, 2016.

FERREIRA, Ana Cláudia Fernandes; FARIA, Joelma Pereira de. Dialetos/ Línguas do Brasil na Desciclopédia. Rua, n. 22, v. 2, p. 549-613, 2016.

FRAGOSO, Élcio Aloisio. O Discurso da Estilística na História da Produçáo Gramatical e na Constituiçáo da Língua Nacional. 2006. Tese (Doutorado) - Instituto de Estudos da Linguagem, Universidade Estadual de Campinas, 2006.

FREITAS, Ronaldo Adriano de. Língua e ensino - objetos paradoxais: a contradição no ensino de língua portuguesa. 2015. Dissertação (Mestrado) - Universidade Federal Fluminense, Niterói, 2015. 
. Análise do funcionamento discursivo dos dicionários online. Anais do VII SAPPIL - Estudos de Linguagem, UFF, n. 1, 2016. p. 562-571.

GARCIA, Dantielli Assumpção. Dicionário da Língua Brasileira: língua, arquivo e discurso. 2008. Dissertaçáo (Mestrado) - Universidade Estadual Paulista, São Paulo, 2008.

A Revista do IHGB e o saber linguístico: um gesto de documentação. 2011.Tese (Doutorado) - Universidade Estadual Paulista, São Paulo, 2011.

. Os instrumentos linguísticos e a autoria na Revista do IHGB. Organon, n. 28, p. 243-261, 2012.

GUIMARÁES, Eduardo. Política de línguas na América Latina. Relatos, $\mathrm{n}$. 7. p. 5-11, 2001.

História da Semântica. Sujeito, sentido e gramática no Brasil. Campinas: Pontes, 2004.

. Multilinguistmo, divisóes da língua e ensino no Brasil. Campinas: CEFIEL/IEL/Unicamp, 2005-10.

A história das ideias linguísticas: um acontecimento decisivo no processo de gramatização brasileira do português. II Jornada de Estudos da Linguagem da UFF, 2011a. Disponível em: <http://www.lis.uff.br/ eduardo-guimaraes-unicamp-ii-jornada-de-estudos-da-linguagem-uff $>$. Acesso em: out. 2018.

O nome da língua. Análise de texto. Procedimentos, análises, ensino. Campinas: RG, 2011 b.

GUILLAUMOU, Jacques; MALDIDIER, Denise. Efeitos do Arquivo. A Análise do Discurso no Lado da História. In: ORLANDI, Eni (Org.). Gestos de Leitura. Da História no Discurso. 2 ed. Campinas: Unicamp, 
1997. p. 163-187.

JOANILHO, Mariangela Peccioli Galli. As metáforas da língua nacional. 2005. Tese (Doutorado) - Instituto de Estudos da Linguagem, Universidade Estadual de Campinas, 2005.

KARIM, Taisir Mahmudo; DI RENZO, Ana Maria. Discursividade entre o civilizado e o selvagem: Ocupação do Sertâo indômito de Mato Grosso. Línguas e Instrumentos Linguísticos, n. 36, p. 21-40, 2015.

LAGAZZI, Suzy. A língua portuguesa no processo de institucionalização da linguística. In: ORLANDI, Eni; GUIMARÃES, Eduardo (Orgs.). Institucionalizaçáo dos estudos da linguagem: a disciplinarização das ideias linguísticas. Campinas: Pontes, 2002. p. 13-22.

O gesto de descrever na Gramática Histórica de Said Ali. In: ALMEIDA, Eliana de; PAROLIN, Maria Inês (Orgs.). Fronteiras de sentidos \& sujeitos nacionais. Campinas: Fapemat; RG, 2012. p. 175186.

LETRAS. Políticas linguísticas: espaços, questóes e agendas. n. 42, 2011.

LETRAS. Língua, museu e patrimônio. n. 46, 2013.

LÍNGUAS E INSTRUMENTOS LINGUÍSTICOS. Campinas: Pontes e Projeto História das Ideias Linguísticas no Brasil. 1998-2008. ISSN 9788571131231. Continuada pela Editora RG. 2009-atual. ISSN 1594906.

LUZ, Mary Neiva Surdi da. Linguística e Ensino: o discurso de entremeio na formação de professores de língua portuguesa. Tese (Doutorado) Universidade Federal de Santa Maria, Santa Maria, 2010.

MACHADO, Carolina de Paula. A designaçáo da palavra preconceito em dicionários atuais. 2007. Dissertação (Mestrado) - Instituto de Estudos da 
Linguagem, Universidade Estadual de Campinas, 2007.

Política e Sentidos da palavra preconceito: uma história no pensamento social brasileiro na primeira metade do século XX. 2011. Tese (Doutorado) - Instituto de Estudos da Linguagem, Universidade Estadual de Campinas, 2011.

MACHADO, Isadora Lima. Para além das palavras e das coisas: Friedrich W. Nietzsche e as Ciências da Linguagem. 2011. Dissertação (Mestrado) - Instituto de Estudos da Linguagem, Universidade Estadual de Campinas, 2011.

- Nietzsche, o destino singular da linguagem. 2015. Tese (Doutorado) - Instituto de Estudos da Linguagem, Universidade Estadual de Campinas, 2015.

MALUF-SOUZA, Olímpia; SILVA, Valdir; ALMEIDA, Eliana; BISINOTO, Leila Salomão Jacob (Orgs.). Redes discursivas: a língua(gem) na pós-graduação. Campinas: Pontes; Unemat, 2012.

MARIANI, Bethania. Colonizaçáo Linguística. Campinas: Pontes, 2004.

MARIANI, Bethania; JOBIM, José Luiz. A questão da língua nacional e a literatura pós-colonial no Brasil. In: PONTES JR., Geraldo; ALMEIDA, Claudia (Orgs.). Relaçóes literárias internacionais: lusofonia e francofonia. Rio de Janeiro: IL/UERJ; Eduff, 2007. p. 40-61.

MARIANI, Bethania; MEDEIROS, Vanise (Orgs.). Ideias linguísticas: formulação e circulação no período JK. Campinas: RG, 2010.

. Disciplinarização dos Estudos em Análise de Discurso. Revista Gragoatá, Niterói, UFF, n. 34, p. 15-25, 2013.

MARTINS, Taís da Silva. Emergência, movimento e deslocamento da disciplinarizaçáo da Análise de Discurso no RS. 2008. Dissertação (Mestrado) - Universidade Federal de Santa Maria, Santa Maria, 2008. 
. Efeitos de sentidos na disciplinarizaçáo de uma teoria. 2012. Tese (Doutorado) - Universidade Federal de Santa Maria, Santa Maria, 2012.

MAZIĖRE, Francine. O enunciado definidor: discurso e sintaxe. In: GUIMARÃES, Eduardo (Org.) História e sentido na linguagem. Campinas: Pontes, 1989. p. 47-59.

- Mazière Francine. Le Dictionnaire de l'Académie française (1694): Initiation d'une pratique normative. In: Archives et documents de la Société d'histoire et d'épistémologie des sciences du langage. Paris, Seconde série, $\mathrm{n}^{\circ} 11,1995$. La genèse de la norme. Colloque de la SHESL, janvier 1994. Textos reunidos por Francine Mazière. pp. 12-17.

MEDEIROS, Vanise. Memória e singularidade no gesto do escritorlexicógrafo. Confluência. Revista do Instituto de Língua Portuguesa, n. 46, p. 143-156, 2014.

Cartografias das línguas: glossários para livros de literatura. Alfa, São Paulo, n. 60, p. 79-93, 2016 a.

. Vocabulário das ruas na caderneta de um escritor. Revista Internacional de Comunicacion y Estudios Linguisticos, v. 5, p. 17-24, 2016b.

MEDEIROS, Vanise; MATTOS, Thiago. O Dialeto Caipira, de Amadeu Amaral: Discurso Fundador e Acontecimento Discursivo. Confluência. Revista do Instituto de Língua Portuguesa, n. 42, p. 152-168, 2012.

MORELLO, Rosangela. A língua portuguesa pelo Brasil: diferença e autoria. 2001. Tese (Doutorado) - Instituto de Estudos da Linguagem, Universidade Estadual de Campinas, 2001.

MOURA, Tatiana Freire de. Mattoso Câmara e suas notícias críticas na revista A Cigarra. 2008. Dissertaçáo (Mestrado) - Universidade Federal 
Fluminense, Niterói, 2008.

NAKAMURA, Ádria Ramos Lustosa. Acesso aberto e recursos educacionais: análise de um discurso oficial. 2016. Dissertaçáo (Mestrado) - Universidade Federal de São Carlos, São Carlos, 2016.

NUNES, José Horta. Discurso e instrumentos linguísticos no Brasil: dos relatos de viajantes aos primeiros dicionários. 1996. Tese (Doutorado) Instituto de Estudos da Linguagem, Universidade Estadual de Campinas, 1996.

. Dicionarização no Brasil: condiçóes e processos. In: NUNES, José Horta; PETTER, Margarida (Orgs.). História do saber lexical e constituiçáo de um léxico brasileiro. São Paulo: Humanitas, Pontes, 2002. p. $99-120$.

- Uma articulação da análise de discurso com a história das ideias linguísticas. Letras, Santa Maria, UFSM, v. 18, n. 2, p. 107-124, 2008a.

O discurso documental na História das Ideias Linguísticas e o caso dos dicionários. Alfa, São Paulo, n. 52, p. 81-100, 2008b.

Nomenclatura de dicionário e discursividades contemporâneas: língua, hiperlíngua e discurso. In: INDURSKY, Freda; FERREIRA, Maria Cristina Leandro; MITTMANN, Solange (Orgs.) O Discurso na Contemporaneidade: materialidades e fronteiras. São Carlos: Claraluz, 2009. p. 1320-1328.

OLIVEIRA, Danilo Ricardo. Política de línguas, política de Estado: história, sentido e espaço de enunciação internacional. 2014. Dissertação (Mestrado) - Instituto de Estudos da Linguagem, Universidade Estadual de Campinas, 2014.

OLIVEIRA, Sheila Elias de. Um espaço de enunciação para dizer os brasileirismos. In: NUNES, José Horta; PETTER, Margarida (Orgs.). 
História do saber lexical e constituição de um léxico brasileiro. São Paulo: Humanitas; Pontes, 2002. p. 83-98.

Cidadania: história e política de uma palavra. 2004. Tese (Doutorado) - Instituto de Estudos da Linguagem, Universidade Estadual de Campinas, 2004.

. O olhar enunciativo de Benveniste sobre o léxico. Organon, n. 30, p. $185-198,2015$.

ORLANDI, Eni. Língua imaginária e língua fluida. Seminário IEL/ Unicamp. Mimeo, 1985.

- (Org.). Política linguística na América Latina. Campinas: Pontes, 1988.

. Terra à Vista. Discurso do confronto: velho e novo mundo. São Paulo: Cortez, 1990.

- (Org.). Discurso Fundador. A Formação do País e a Construção da Identidade Nacional. Campinas: Pontes, 1993a.

. Prefácio. In: ORLANDI, Eni (Org.). Discurso Fundador. A Formação do País e a Construção da Identidade Nacional. Campinas: Pontes, 1993b. p. 07-09.

Vão Surgindo Sentidos. In: ORLANDI, Eni (Org.) Discurso Fundador. A Formação do País e a Construção da Identidade Nacional. Campinas: Pontes, 1993c. p. 11-25.

. Ética e Política Linguística. Línguas e instrumentos linguísticos, Campinas, Pontes, n. 1, p. 7-16, 1998.

. (Org.). História das ideias linguísticas: construção do saber metalinguístico e constituição da língua nacional. Campinas: Pontes; 
Cáceres: Unemat, 2001.

Língua e conhecimento linguístico: para uma história das ideias no Brasil. São Paulo: Cortez, 2002a.

A Análise de Discurso e seus Entremeios: Notas a sua História no Brasil. Cadernos de Estudos Linguísticos. História das Ideias Linguísticas, Campinas, Unicamp, n. 42, p. 21-40, 2002 b.

. (Org.). Política linguística no Brasil. Campinas: Pontes, 2007a.

- O processo de descolonização e "lusofonia". Línguas e Instrumentos Linguísticos, n. 19, p. 20, 2007b.

. Língua Brasileira e outras histórias. Discurso sobre a língua e ensino no Brasil. Campinas: Pontes, 2009.

. J. Peytard: l'exercice de la transversalité. Synergies Monde, v. 10, p. 91-100, 2013.

Ciência da Linguagem e Política: Anotaçôes ao pé das Letras. Campinas: Pontes, 2014.

ORLANDI, Eni; GUIMARÃES, Eduardo (Orgs.). Língua e cidadania. O português no Brasil. Campinas: Pontes, 1996 .

Apresentação. Identidade linguística. In: ORLANDI, Eni; GUIMARÁES, Eduardo (Orgs.). Língua e cidadania. O português no Brasil. Campinas: Pontes, 1996b. p. 09-15.

; GUIMARÃES, Eduardo (Orgs.). Institucionalizaçáo dos estudos da linguagem: a disciplinarização das ideias linguísticas. Campinas: Pontes, 2002.

; GUIMARÃES, Eduardo (Orgs.). Un dialogue atlantique. Lyon: 
ENS Éditions, 2007.

; SOUZA, Tania Clemente de. Língua imaginária e língua fluida:

dois métodos de trabalho com a linguagem. In: ORLANDI, Eni (Org.). Política linguística na América Latina. Campinas: Pontes, 1988. p. 27-40.

PAYER, Maria Onice. Memória da língua. Imigração e nacionalidade. 1999. Tese (Doutorado) - Instituto de Estudos da Linguagem, Universidade Estadual de Campinas, 1999.

. O Lugar do imigrante entre a língua materna e a língua nacional brasileira. Versão Beta, São Carlos, UFSCar, v. 29, n. 29, p. 1-14, 2004.

. Processos de identificação sujeito/língua. Ensino, língua nacional e língua materna. In: ORLANDI, Eni (Org.). Política linguística no Brasil. Campinas: Pontes, 2007. p. 113-123.

PÊCHEUX, Michel. Ler o Arquivo Hoje. In: ORLANDI, Eni (Org.). Gestos de Leitura. Da História no Simbólico. 2. ed. Campinas: Editora da Unicamp, 1997. p. 55-66.

PETRI, Verli. Por um acesso fecundo ao arquivo. Revista Letras: Corpus: Análise de Dados e Cultura Acadêmica, n. 21, p. 121-125, 2000.

- Gramatização das línguas e instrumentos linguísticos: a especificidade do dicionário regionalista. Línguas e Instrumentos Linguísticos, n. 29. p. 23-37, 2012.

PETRI, Verli; SCHNEIDERS, Caroline Malmann; SCHERER, Amanda. A língua nacional de João Ribeiro: alguns apontamentos. Polifonia, Cuiabá, v. 22, n. 31, p. 53-72, 2015.

PFEIFFER, Claudia. Bem dizer e retórica: um lugar para o sujeito. 2000. Tese (Doutorado) - Instituto de Estudos da Linguagem, Universidade Estadual de Campinas, 2000. 
. A língua nacional no espaço das polêmicas do século XIX/XX. In: ORLANDI, Eni (Org.). História das Ideias Linguísticas: Construção do Saber Metalinguístico e Constituição da Língua Nacional. Cáceres: Unemat; Campinas: Pontes, 2001. p. 167-183.

Língua, ensino e políticas públicas. In: CONFORTE, André; VALENTE, André Crim (Orgs.). Saber a Língua, Saber da Língua. Rio de Janeiro: UERJ, 2011a. p. 97-109.

A obra didática de Frei Caneca na História das Ideias Linguísticas: configuraçôes de um poder dizer. Letras, Santa Maria, UFSM, v. 42, p. 251-283, $2011 b$.

Abralin, GEL e Anpoll - Espaços de institucionalização da Linguística. In: M_ALUF-SOUZA, Olímpia; ALMEIDA, Eliana de; SILVA, Valdir; BISINOTO, Leila Salomáo. (Orgs.). Discurso, sujeito e memória. Campinas: Pontes, 2012. p. 47-58.

Instauração de um lugar de pesquisa, de uma posição pesquisadora - tributo a Eni Orlandi. Traços de linguagem. Revista de estudos linguísticos, Cáceres, n. 2, p. 29-35, 2018.

LETRAS. Políticas linguísticas: espaços, questóes e agendas, n. 42, 2011.

LETRAS. Língua, museu e patrimônio, n. 46, 2013.

RIBEIRO, Thales de Medeiros. Jogo das regras, jogo sobre as regras: real da língua e jogo na obra de Michel Pêcheux. 2016. Dissertação (Mestrado) - Instituto de Estudos da Linguagem, Universidade Estadual de Campinas, 2016.

RODRÍGUEZ, Carolina. Língua, Nação e Nacionalismo: um estudo sobre o Guarani no Paraguai. 2000. Tese (Doutorado) - Instituto de Estudos da Linguagem, Universidade Estadual de Campinas, 2000.

SARIAN, Maristela Cury. A injunçáo ao novo e a repetiçáo do velho: um 
olhar discursivo ao Programa Um Computador por Aluno (PROUCA). 2012. Tese (Doutorado) - Instituto de Estudos da Linguagem, Universidade Estadual de Campinas, 2012.

SANTOS, Gleide Amaral dos. A Formulaçáo das regras e dos acréscimos nas gramáticas de Júlio Ribeiro, Said Ali e Evanildo Bechara. 2013. Tese (Doutorado) - Instituto de Estudos da Linguagem, Universidade Estadual de Campinas, 2013.

SCHREIBER DA SILVA, Soeli Maria; SANTOS, Gabriel Leopoldino dos. As textualizaçóes do político: modos de inscrição da língua na história e no social - a cooficilização das línguas em São Miguel da Cachoeira. In: RODRIGUES, Eduardo Alves; SANTOS, Gabriel Leopoldino dos; CASTELO BRANCO, Luiza Kátia (Orgs.). Análise do Discurso no Brasil: Pensando o Impensado Sempre. Campinas: RG, 2011. p. 273-291.

SCHERER, Amanda Eloina. Linguística no Sul: estudos das ideias e organização da memória. In: GUIMARĀES, Eduardo; BRUM DE PAULA, Mirian Rose. Sentido e Memória. Campinas; Pontes, 2005. p. 09-27.

; COSTA, Maria Iraci.; BILIÁO, Maurício. Uma carta e sua discursividade na história da problemática do nome da língua no/do Brasil na década de 1930. Diálogo das Letras, n. 6. p. 159-175, 2017.

; PETRI, Verli. Le mouvement et les déplacements des études sur le discours à partir des années 1980 et leur disciplinarisation: le cas brésilien. Analyse du discours dans la societé: engagement du chercheur et demande social, Paris: Éditions Champion, Honoré Champion, p. 55-65, 2012.

; PETRI, Verli. O movimento disciplinar sobre os estudos do discurso, no contexto brasileiro, a partir dos anos 1980. Desenredo, Passo Fundo, Universidade de Passo Fundo, v. 9, n. 2, p. 284-294, jul./dez. 2013.

SCHNEIDERS, Caroline Mallmann. Atravessamento de saberes nos estudos sobre a linguagem no/do Brasil nos anos 50. 2011. Dissertação (Mestrado) - Universidade Federal de Santa Maria, Santa Maria, 2011. 
. Do retorno ao arquivo à constituição do corpus e dos gestos de interpretação. Conexáo Letras, v. 9, n. 11, p. 99-109, 2014 a.

Serafim da Silva Neto: entre a constituição e a circulaçáo do conhecimento linguístico. 2014. Tese (Doutorado) - Universidade Federal de Santa Maria, Santa Maria, 2014b.

A língua do/no Brasil: efeitos da memória e da história. Gragoatá, Niterói, v. 22, n. 42, p. 329-344, 2017.

; REISDORFER, Cleiton. A constituição dos livros didáticos pela determinação das teorias linguísticas. Matraga, n. 24, p. 47-66, 2017.

SCHUMM, Gabriele de Souza e Castro. Um estudo enunciativo de política de línguas: Uma identidade Misturada. 2004. Dissertação (Mestrado) - Instituto de Estudos da Linguagem, Universidade Estadual de Campinas, 2004.

. Um estudo enunciativo sobre política de línguas e mudança linguística. 2009. Tese (Doutorado) - Instituto de Estudos da Linguagem, Universidade Estadual de Campinas, 2009.

SCOTTA, Larissa. Da enciclopédia enquanto um círculo que se fecha à WIKIPÉDIA enquanto uma rede que se abre: um gesto interpretativo. 2008. Dissertação (Mestrado) - Universidade Federal de Santa Maria, Santa Maria, 2008.

SILVA, Lourdes Serafim; BRESSANIN, Joelma Aparecida. O ensino de línguas na região de fronteira: processos de subjetivação do aluno imigrante. Gragoatá, Niterói, v. 22, n. 42, p. 308-328, 2017.

SILVA, José Renato. A LDB de 1961: Língua e Educação na configuração nacional - Um percurso na História. Campinas: Unicamp, 2010.

SILVA, Mariza Vieira da. História da alfabetizaçáo no Brasil. A constituição 
de sentidos e do sujeito da escolarizaçáo. Tese (Doutorado) - Instituto de Estudos da Linguagem, Universidade Estadual de Campinas, 1998.

. Le mouvement et les déplacements de la disciplinarisation des savoirs linguistiques au Brésil: historicité, sujet et société contemporaine. Histoire Epistémologie Langage, n. 5, p. 1-9, 2012.

. Língua nacional, escola nacional. In: PETRI, Verli; DIAS, Cristiane (Orgs.). Análise do Discurso em perspectiva: teoria, método e análise. Santa Maria: Editora da UFSM, 2013. p. 297-310.

SILVA SOBRINHO, José Simão. "A língua é o que nos une": língua, sujeito e Estado no Museu da Língua Portuguesa. Tese de Doutorado. Campinas: IEL/Unicamp, 2011.

SILVESTRE, Simone Michelle. Política de línguas em Timor-Leste: passado, presente e futuro na constituição do Estado-Naçáo. 2016. Tese (Doutorado) - Instituto de Estudos da Linguagem, Universidade Estadual de Campinas, 2016.

STURZA, Eliana Rosa. Línguas de fronteiras e políticas de línguas: uma história das ideias linguísticas. 2006. Tese (Doutorado) - Instituto de Estudos da Linguagem, Universidade Estadual de Campinas, 2006.

ZOPPI-FONTANA, Mónica (Org.). O Português do Brasil como Língua Transnacional. Campinas: RG, 2009a.

. O Português do Brasil como Língua Transnacional. In: ZOPPI FONTANA, Mónica. (Org.). O Português do Brasil como Língua Transnacional. Campinas: RG, 2009b. p. 13-42.

Equívocos da/na língua oficial. In: PETRI, Verli; DIAS, Cristiane (Orgs.). Análise do Discurso em perspectiva: teoria, método e análise. Santa Maria: Editora da UFSM, 2013. p. 275-296. 
Língua oficial e políticas públicas de equidade de gênero. Línguas e Instrumentos Linguísticos, n. 36, p. 221-243, 2015.

DOI - http://dx.doi.org/10.5902/2179219436580 